\title{
MONTHLY MEAN PRESSURE RECONSTRUCTION FOR THE LATE MAUNDER MINIMUM PERIOD (AD 1675-1715)
}

\author{
J. LUTERBACHER ${ }^{\mathrm{a}, *}$, R. RICKLI ${ }^{\mathrm{a}}$, C. TINGUELY ${ }^{\mathrm{a}}$, E. XOPLAKI ${ }^{\mathrm{a}, \mathrm{e}}$, E. SCHÜPBACH $^{\mathrm{a}}$, D. DIETRICH ${ }^{\mathrm{b}}, \mathrm{J}$. HÜSLER ${ }^{\mathrm{b}}$, \\ M. AMBÜHL ${ }^{b}$, C. PFISTER ${ }^{\mathrm{c}}$, P. BEELI ${ }^{\mathrm{c}}$, U. DIETRICH ${ }^{\mathrm{c}}$, A. DANNECKER ${ }^{\mathrm{c}}$, T.D. DAVIES ${ }^{\mathrm{d}}$, P.D. JONES ${ }^{\mathrm{d}}$, \\ V. SLONOSKY ${ }^{\mathrm{d}}$, A.E.J. OGILVIE ${ }^{\mathrm{e}}$, P. MAHERAS ${ }^{\mathrm{f}}$, F. KOLYVA-MACHERA ${ }^{\mathrm{g}}$, J. MARTIN-VIDE ${ }^{\mathrm{h}}$, M. BARRIENDOS ${ }^{\mathrm{h}}$, \\ M.J. ALCOFORADO', M.F. NUNES', T. JÓNSSON ${ }^{k}$, R. GLASER ${ }^{1}$, J. JACOBEIT ${ }^{1}$, C. BECK ${ }^{1}$, A. PHILIPP ${ }^{1}$, U. BEYER ${ }^{1}$, \\ E. KAAS ${ }^{\mathrm{m}}$, T. SCHMITH ${ }^{\mathrm{m}}$, L. BÄRRING ${ }^{\mathrm{n}}$, P. JÖNSSON ${ }^{\circ}$, L. RACZ ${ }^{\mathrm{p}}$ and H. WANNER \\ anstitute of Geography, University of Bern, $\mathrm{CH}-3012$ Bern, Switzerland \\ ${ }^{\mathrm{b}}$ Institute of Mathematical Statistics and Actuarial Sciences, CH-3012 Bern, Switzerland \\ ${ }^{\mathrm{c}}$ Institute of History, University of Bern, CH-3000 Bern 9, Switzerland \\ ${ }^{\mathrm{d}}$ Climatic Research Unit, University of East Anglia, Norwich, Norfolk, NR4 7TJ, UK \\ ' INSTAAR, University of Colorado, Boulder, CO 80309-0450, USA \\ ${ }^{\mathrm{f}}$ Department of Meteorology and Climatology, University of Thessaloniki, GR-54006 Thessaloniki, Greece \\ ${ }^{g}$ Department of Mathematics, University of Thessaloniki, GR-54006 Thessaloniki, Greece \\ ${ }^{\mathrm{h}}$ Departimento de Geografia Fisica, University of Barcelona, E-08028 Barcelona, Spain \\ ${ }^{i}$ Departimento de Geografia, Universidade de Lisboa, P-1699 Lisboa, Portugal \\ j Departimento de História, Universidade de Évora, P-7000 Évora, Portugal \\ ${ }^{\mathrm{k}}$ lcelandic Meteorological Office (Vedurstofa Island), IS-150 Reykjavik, Iceland \\ ${ }^{1}$ Institute of Geography, Julius-Maximilian-Universität, Würzburg, D-97074 Würzburg, Germany \\ m Danish Meteorological Institute, Lyngbyvej 100, DK-2100 Copenhagen, Denmark \\ ${ }^{\mathrm{n}}$ Department of Physical Geography, Lund University, Box 118, S-22100 Lund, Sweden \\ - Malmo University, S-20506 Malmo, Sweden \\ p Szeged University Alliances, Juhasz Gyula College, Hattya sor 10, H-6725 Szeged, Hungary
}

\begin{abstract}
The Late Maunder Minimum (LMM; 1675-1715) delineates a period with marked climate variability within the Little Ice Age in Europe. Gridded monthly mean surface pressure fields were reconstructed for this period for the eastern North Atlantic-European region $\left(25^{\circ} \mathrm{W}-30^{\circ} \mathrm{E}\right.$ and $\left.35-70^{\circ} \mathrm{N}\right)$. These were based on continuous information drawn from proxy and instrumental data taken from several European data sites. The data include indexed temperature and rainfall values, sea ice conditions from northern Iceland and the Western Baltic. In addition, limited instrumental data, such as air temperature from central England (CET) and Paris, reduced mean sea level pressure (SLP) at Paris, and monthly mean wind direction in the Øresund (Denmark) are used. The reconstructions are based on a canonical correlation analysis (CCA), with the standardized station data as predictors and the SLP pressure fields as predictand. The CCA-based model was performed using data from the twentieth century. The period 1901-1960 was used to calibrate the statistical model, and the remaining 30 years (1961-1990) for the validation of the reconstructed monthly pressure fields. Assuming stationarity of the statistical relationships, the calibrated CCA model was then used to predict the monthly LMM SLP fields. The verification results illustrated that the regression equations developed for the majority of grid points contain good predictive skill. Nevertheless, there are seasonal and geographical limitations for which valid spatial SLP patterns can be reconstructed. Backward elimination techniques indicated that Paris station air pressure and temperature, CET, and the wind direction in the Øresund are the most important predictors, together sharing more than $65 \%$ of the total variance. The reconstructions are compared with additional data and subjectively reconstructed monthly pressure charts for the years $1675-1704$. It is shown that there are differences between the two approaches. However, for extreme years the reconstructions are in good agreement.
\end{abstract}

KEY WORDS: canonical correlation analysis; Europe; Maunder Minimum; proxy data; sea level pressure reconstruction * Correspondence to: Institute of Geography, University of Bern, Hallerstr. 12, CH-3012, Bern, Switzerland. e-mail:
juerg@giub.unibe.ch 


\section{INTRODUCTION}

The Maunder Minimum (MM; 1645-1715) denotes the coldest period of the so-called Little Ice Age (LIA; variously assessed as AD 1300-1900). The MM is well known for its scarcity of sunspots, as first recognized by Spörer (1887) and Maunder (1922), and later confirmed by Eddy (1976). A low number of sunspots is a direct indication of less intense solar radiation and activity. Estimations about the total solar radiative output changes for the $\mathrm{MM}$ are in the order of $0.2-0.4 \%$ relative to present levels (Hoyt and Schatten, 1993; Nesme-Ribes et al., 1993; Zhang et al., 1994; Lean et al., 1995; Beer et al., 1996; Lean and Rind, 1998, 1999; Maddox, 1998). The solar activity during the MM was near its lowest levels within the past 8000 years (Lean and Rind, 1999) and the UV (200-300 nm) irradiance was also lower (Lean et al., 1995). This in turn could have had an influence on stratospheric chemistry (ozone)/dynamics (absorption) activities. Accordingly, levels of $\delta^{14} \mathrm{C}$ and $\delta^{10} \mathrm{Be}$ cosmogenic isotopes in, respectively, tree rings and ice cores were elevated (Eddy, 1976; Stuiver and Braziunas, 1993), while stratospheric ozone was reduced and cloudiness was probably increased (Wuebbles et al., 1998). Further, the MM was characterized by the eruption of several large volcanoes (Briffa et al., 1998) and by marked climate variability in large areas of the entire world. The reconstructed global-scale temperature patterns over the last 600 years by Mann et al. (1998) showed pronounced cold periods during the mid and late seventeenth century. The reconstructed annual mean Northern Hemisphere $(\mathrm{NH})$ surface temperatures were $0.2-0.4^{\circ} \mathrm{C}$ lower compared with the reference period of 1902-1980. It is interesting to note that, from 1610 to 1800 , the correlation of reconstructed solar irradiance and $\mathrm{NH}$ temperature is 0.86 , implying a predominant solar influence in this pre-industrial period (Lean and Rind, 1998). Concerning Europe, the surface temperatures were at times reduced in the order of $0.7^{\circ} \mathrm{C}$ compared with twentieth century conditions, especially in the northern part of the continent (Bradley and Jones, 1993; Damon and Jirikowic, 1994).

Within the MM, the Late Maunder Minimum (LMM; 1675-1715) is of particular interest from a climatological point of view in many parts of Europe, since a large amount and a broad spectrum of high resolution multi-proxy data (monthly, seasonal) and instrumental data are available (Wanner et al., 1995; Luterbacher and Pfister, 1999; Luterbacher et al., 1999; Pfister, 1999). It was one of the few very cold periods in the last centuries that persisted over decades. In particular, European winters and springs were more severe then than during the twentieth century. It is an interesting feature that the cooling of winters began in the mid-1670s over Western Europe and the British Isles (Pfister, 1994, 1999). Five years later it spread to Central Europe and finally reached Eastern Europe around 1684. The climax of the LIA was reached in the 1690s, with extremely dry winters having recurrent long lasting and strong advection of continental air from the northeast towards western Russia and Europe (Borisenkov, 1994; Brázdil et al., 1994; Pfister, 1994, 1999; Kington, 1995, 1997, 1999; Wanner et al., 1995; Luterbacher and Pfister, 1999; Luterbacher et al., 2000). The Late Maunder Minimum (1675-1715) - a key period for studying decadal scale climate change in Europe). The reduction of the winter mean temperatures over wide areas of Europe is estimated to be of the order of $1-1.5^{\circ} \mathrm{C}$ (Pfister, 1994, 1999). Similar drops of winter mean temperatures are visible in the well-known central England temperature (CET) series (Manley, 1974; Parker et al., 1992). Jones et al. (1998) indicates that the most severe decade of the millennium over the Northern Hemisphere was from 1691 to 1700 , being around $0.7^{\circ} \mathrm{C}$ lower than the period $1961-1990$. The summers, generally, were much wetter and cooler in Western, Central and Eastern Europe (Wanner et al., 1995; Pfister, 1999; Luterbacher et al., 2000). According to Kington (1999), warming began in 1699, first over the British Isles, then reaching western Central Europe in 1704 and finally eastern Central Europe at the end of the LMM (Pfister, 1999).

Persistent low temperatures and different hygric conditions over large parts of Europe have their origin in a marked change of the atmospheric circulation. Until now, only a limited number of atmospheric circulation patterns for the LMM on a monthly or seasonal resolution have been reconstructed. Lamb $(1977,1982)$ reconstructed seasonal mean sea level pressure (SLP) maps for specific severe winters within the LMM (e.g. 1684/1685) period and averaged the January and July patterns from 1690 to 1699 with the estimation of absolute SLP by drawing isobars. Qualitatively reconstructions of the LMM monthly mean air pressure distribution (estimates of the main active air pressure centres over Europe as well as 
indications of the advection of the main air masses, without assessing numerical air pressure values) have been done by Wanner et al. (1994, 1995). The investigators relied on a few early instrumental records, such as CET (starting in January 1659; Manley, 1974; Parker et al., 1992) and high-resolution documentary proxy data. These records included indexed temperature and rainfall data for specific areas, information about various important weather elements (e.g. number of rainy days, direction of cloud movement, wind direction), and documentary data on related events, such as warm and cold spells, freezing of water bodies, droughts, floods, advanced or delayed vegetation in particular European regions. From this disparate information, they produced qualitative mean monthly pressure maps for the winter and spring months for the three decades from 1675 to 1704. Hochstrasser (1995) produced charts for the summer and autumn months in a similar way for the same period. One important strength of the qualitative reconstructions is the omnipotence it grants to the investigator, integrating synoptic knowledge of past and future climate conditions (Yarnal and Frakes, 1997). Nevertheless, there are several drawbacks with manual reconstructions, such as the dependence on assigning information from documentary evidence on the reconstruction subject appearing to be most important of these. Furthermore, the inherent subjectivity of the method and the freedom and power it gives to the investigator increases the danger of inconsistent categorization and makes a replication of the reconstruction difficult (Yarnal, 1993; Yarnal and Frakes, 1997). For instance, the significance of extreme episodes, which are generally extensively described within documentary sources, tend to be overestimated with respect to their influence on the entire month's average character (Wanner et al., 1995). This is particularly the case when more normal climate/weather conditions are inadequately documented.

The drawbacks of the subjectivity of hand-drawn synoptic pressure patterns led to the idea of a new reconstruction of the existing LMM monthly air pressure fields based on objective statistical techniques. This was one of the five main aims (see Jones et al., 1999 for a description of the other aims) of the Annual to Decadal Variability In Climate in Europe (ADVICE) research project, funded by the European Community.

The most rewarding approach in reconstructing past climate from documentary evidence is based on multivariate statistical techniques and twentieth century instrumental data. It aims to define the relationship between the large-scale patterns of the atmospheric circulation over the North Atlantic-European area and specific sets of instrumental station data (e.g. pressure, temperature and precipitation). The statistical relationships derived in the twentieth century can be applied to the data in the period to be reconstructed. Jones et al. (1999) produced monthly SLP charts back to 1780 for Europe by using a PCA regression technique, which relates gridded surface air pressure patterns to 51 station pressure series. Briffa et al. (1987) used spatial regression technique to reconstruct anomaly SLP patterns for Europe prior to 1873 , based on ring-width chronologies and a small number of maximum latewood density chronologies. Cook et al. (1994) reviewed and compared two alternative spatial regression methods (orthogonal spatial regression (OSR) and canonical regression (CR)) used in dendroclimatology to reconstruct monthly mean sea level pressure back to 1750 . These studies show the potential for tree-ring or station data to reconstruct extended pressure fields for the pre-observational period based on objective methods, to a reasonable degree of precision and confidence. In this study, we used the canonical correlation analysis (CCA) to reconstruct the LMM (1675-1715) pressure fields based on several consistent and highly resolved climatological time series (see Section 2), which were prepared and analysed within ADVICE. The stationarity of the statistical relationships in these studies are assumed, thus patterns during the twentieth century are applicable to earlier epochs. This assumption applies to all paleo reconstruction studies. Circulation patterns change with time but it is assumed that the relationships between the variables such as temperature or rainfall do not alter with time. In addition, global average SLP can not change but patterns will alter in different periods and it is these that influence the surface climate patterns. The year-to-year variability is much greater than the long-term climate change (whether anthropogenic or natural, whether solar or IR), thus the regression-type relationships derived in this paper are almost entirely based on high-frequency relationships. Longer time-scale variability is relatively small in this regard. Longer time-scale change over the 1675-present period is not that great anyway (the 1730s, for example, are only slightly cooler than the 1980s). In addition, using methods such as those presented 
in this paper produce far more reliable reconstructions than proxy data (trees, ice cores, etc.) as we can derive indices on a monthly basis and not just for a season or year. In addition, due to the objectiveness of this reconstruction procedure, it has some advantages compared with the subjective reconstructions presented earlier. In particular, new station data can be included in the model and the quality of the resulting SLP reconstructions can be verified by statistical methods using independent SLP data withheld from the calibration exercise.

The paper is structured as follows. Section 2 gives a detailed layout of the available continuous data in the LMM and the respective data sources for the twentieth century. Section 3 describes the statistical model used to reconstruct monthly SLP for the LMM. The spatial and overall model performance for the twentieth century described in Section 4 provides an idea of the reconstruction quality that might be obtained for the LMM. In the Section 5, the monthly LMM reconstructions are compared with data not used in the calibration procedure. This data could not be used in calibration, as the series were not entirely continuous. A discussion and conclusions are presented in Section 6.

\section{DATA}

\subsection{Data base for the LMM}

Most of the climate information for the LMM originates from the Euro-Climhist data pool. This is a large body of documentary data on the climate history of Europe for the last 1000 years (Pfister, 1994, 1999).

Proxy data are the most important source of weather and climate information for the LMM. However, some instrumental series are also available (see below), which potentially allow a more reliable reconstruction of the climate characteristics. The proxy data set for the LMM was improved by the incorporation of previously undetected high-resolution documentary (descriptive and serial proxy data) evidence. In particular, new continuous indexed data, mostly referring to the thermic and hygric conditions over specific European areas, were prepared by several ADVICE partners. These indices are integer values between +3 and -3 . The grades of +3 and -3 are applied to those months that are documented with proxy data and can unmistakably be considered as 'extreme' by twentieth century standards (i.e. they are beyond two standard deviations (S.D.) from the mean of the reference period 1901-1960). The grades of +2 and -2 (between 1.4 and 2.0 S.D. from the mean of the period 1901-1960) are applied to the less extreme cases that are documented with proxy data. The grades of +1 and -1 are applied to all those cases that are only documented with descriptive information (between 0.7 and 1.4 S.D. from the mean of the reference period). A grade of 0 is applied to cases that correspond to the average climate of the period 1901-1960 (Pfister et al., 1994; Pfister, 1999). Serial proxy data provide an incomplete record of climate variations and different series are likely to represent different climatic variables. These proxy series represent an integration of a number of climate parameters, although one parameter may be more important than the others. In addition, associations between the climates of different regions occur because of the large-scale patterns of the atmospheric circulation, and these can provide a basis for comparing different instrumental and proxy climate series (Gordon et al., 1985).

The available continuous monthly (or seasonal) indexed data, which cover the period of the LMM, are presented in Table I. These are used for the SLP reconstructions. No interpretation about the reliability of the climate descriptions, the different sources, the reconstruction technique, nor the quality control procedures for these indices are given in this study, since they are published elsewhere. The relevant references can also be found in Table I. In addition to the continuous proxy indices, some instrumental time series with a monthly resolution are available for the whole 41-year period. These time series are also presented in Table I and were included in the reconstruction procedure. Figure 1(b) shows the geographical location of the continuous or sporadic data available for the LMM listed in Table I. In the best case, a total of 21 independent variables (predictors) for winter, 19 for both spring and summer, and 18 for autumn were integrated into the reconstruction approach. 
Table I. Compilation of available monthly or seasonal indexed and measured data during the LMM that have been used in the reconstruction model

\begin{tabular}{|c|c|c|c|c|c|}
\hline Data type & Country & Station/area & $\begin{array}{l}\text { Meteorological } \\
\text { parameter }\end{array}$ & Time period & References \\
\hline \multirow{9}{*}{$\begin{array}{c}\text { Indexed } \\
\text { series }\end{array}$} & Greece & Athens & $\mathrm{T}$ and $\mathrm{R}$ & All & Xoplaki et al., 2000 \\
\hline & Portugal & $\begin{array}{l}\text { Southern part } \\
\text { (Lisbon and Évora) }\end{array}$ & $\mathrm{T}$ and $\mathrm{R}$ & All & $\begin{array}{l}\text { Alcoforado et al., } \\
2000\end{array}$ \\
\hline & Switzerland & Swiss Plateau & $\mathrm{T}$ and $\mathrm{R}$ & All & Pfister, 1994, 1999 \\
\hline & Hungary & 'Ancient' Hungary & $\mathrm{T}$ and $\mathrm{R}$ & All & Rácz, 1994, 1999 \\
\hline & Germany & Southern parts & $\mathrm{T}$ & All & $\begin{array}{l}\text { Glaser, 1997; Glaser } \\
\text { et al., } 1999\end{array}$ \\
\hline & Spain & $\begin{array}{l}\text { Murcia, Madrid, } \\
\text { Sevilla and } \\
\text { Barcelona }\end{array}$ & $\mathrm{R}$ & All & $\begin{array}{l}\text { Martin-Vide and } \\
\text { Barriendos, } 1995\end{array}$ \\
\hline & England & $\begin{array}{l}\text { Southern part } \\
\text { (Kew) }\end{array}$ & $\mathrm{R}$ & All & Siegenthaler, 1994 \\
\hline & Iceland & $\begin{array}{l}\text { North, northwest, } \\
\text { east and south off } \\
\text { the Icelandic coast }\end{array}$ & $\begin{array}{l}\text { Number of weeks } \\
\text { with sea ice }\end{array}$ & All & $\begin{array}{l}\text { Ogilvie, 1992, 1996; } \\
\text { Ogilvie and } \\
\text { Jónsdóttir, } 1996\end{array}$ \\
\hline & $\begin{array}{l}\text { Denmark/ } \\
\text { Germany }\end{array}$ & Western Baltic & $\begin{array}{l}\text { Western Baltic sea } \\
\text { ice severity index }\end{array}$ & Winter averages & $\begin{array}{l}\text { Koslowski and } \\
\text { Glaser, 1995, } 1999\end{array}$ \\
\hline \multirow[t]{6}{*}{$\begin{array}{l}\text { Measured } \\
\text { series }\end{array}$} & France & Paris & $\begin{array}{l}\text { Station air } \\
\text { pressure }\end{array}$ & $\begin{array}{l}\text { January } 1675- \\
\text { June } 1713\end{array}$ & $\begin{array}{l}\text { Legrand and Le } \\
\text { Goff, } 1992\end{array}$ \\
\hline & France & Paris & $\mathrm{T}$ & $\begin{array}{l}\text { January } 1676- \\
\text { December } 1992\end{array}$ & $\begin{array}{l}\text { Legrand and Le } \\
\text { Goff, } 1992\end{array}$ \\
\hline & England & Central England & $\mathrm{T}(\mathrm{CET})$ & All & Manley, 1974 \\
\hline & England & Kew & $\mathrm{R}$ & $1697-1715$ & Wales-Smith, 1971 \\
\hline & Netherlands & De Bilt & $\mathrm{T}$ & Winter averages & $\begin{array}{l}\text { Van den Dool et } \\
\text { al., } 1978\end{array}$ \\
\hline & Denmark & Øresund & $\begin{array}{l}\text { Wind direction } \\
\text { (DD) }\end{array}$ & $\begin{array}{l}35 \% \text { of all } \\
\text { months, not } \\
\text { continuous }\end{array}$ & $\begin{array}{l}\text { Frydendahl et al., } \\
\text { 1992; Frich, Personal } \\
\text { communication }\end{array}$ \\
\hline
\end{tabular}

Columns 2-4 include the available meteorological parameter for the corresponding countries and areas. $\mathrm{T}$ denotes station temperature and $\mathrm{R}$ stands for precipitation. Column 5 gives the time period for which data are available. All refers to continuous data for the whole 41-year period. The last column gives the references where details about the sources used, the reconstruction technique and the quality control of the meteorological parameters can be found.

Other important LMM data series, such as the compilation of severe climate conditions (cold/hot; wet/dry) in the vicinity of Moscow and the Ukraine (Lyakhov, 1987; Borisenkov, 1994), Romania (Boroneant and Chiper, 1998) and the dominant wind direction at Kew, Paris and Breslau (today Wroclaw, $51.1^{\circ} \mathrm{N}, 16.88^{\circ} \mathrm{E}$; Poland) are not continuous over the entire LMM, and are therefore omitted from the reconstruction procedure. Instead they are used for an independent check on the reconstruction results. The results of these 'additional' verification checks will be presented in Section 5.

\subsection{Data base for the twentieth century}

2.2.1. Predictor data (station data). For the twentieth century, there are several decades of observed data sets relevant to the above-mentioned meteorological variables and indices used as predictors for the LMM. These station data for temperature, precipitation and air pressure from 1901 to 1990 were extracted from the World Climate Disc (1992) and from the following publications: World Weather Records, Monthly Climatic Data for the World, Reseau Mondial and from GHCN (Vose et al., 1992; Peterson et al., 1998). The Spanish rainfall data were obtained from Instituto National de Meteorologia, Madrid. Data (monthly or seasonal) for which only indexed values exist during the LMM, were reduced to a integer value between +3 and -3 in order to put them on an equivalent level (see Section 2.1). 

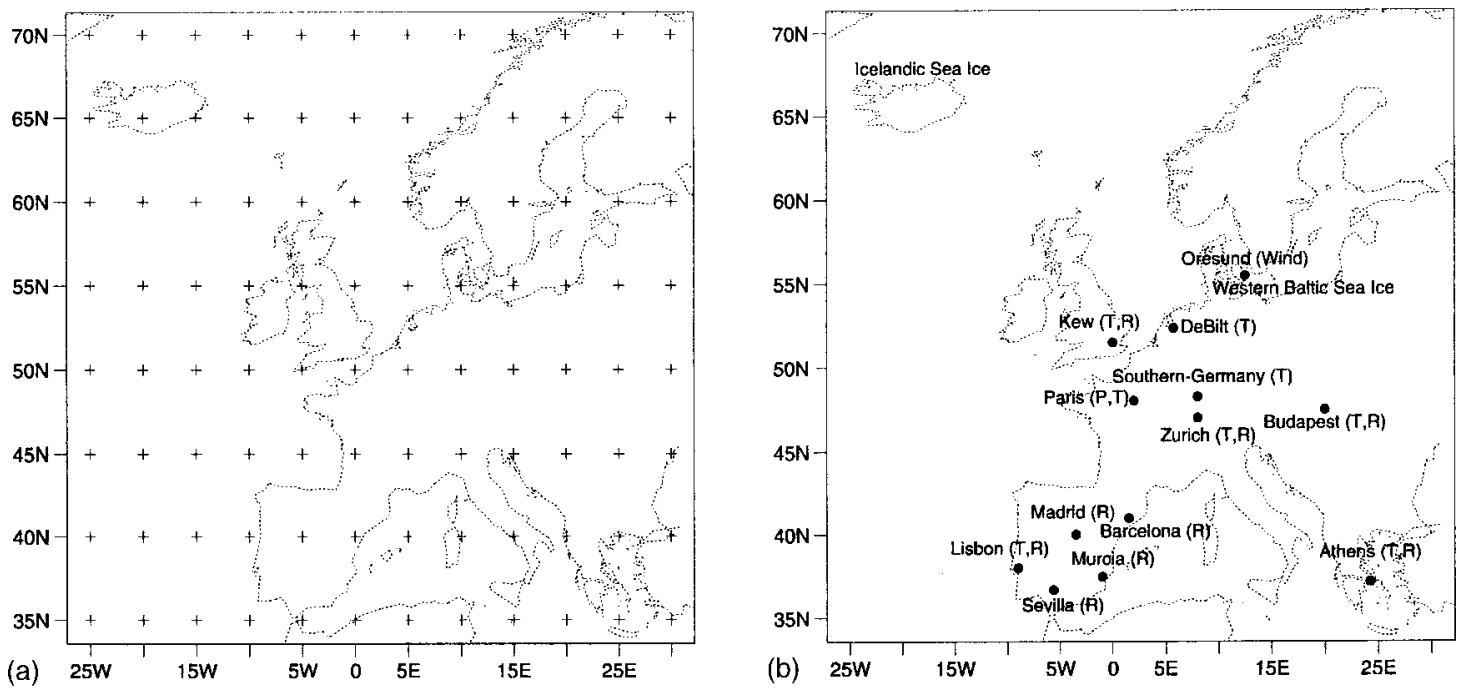

Figure 1. (a) Domain of the area to be reconstructed and analysed; 96 grid points (predictands) (rectangular $5^{\circ} \times 5^{\circ}$ grid) are used to represent the SLP field in this study. The grid points are not equally weighted in the analysis. (b) Continuous or sporadic data availability for the LMM, resulting in a total of 21 independent variables (predictors) for winter, 19 for spring and summer and 18 for autumn, which are integrated in the statistical reconstruction model. $\mathrm{P}$ denotes station pressure, $\mathrm{T}$ station temperature and $\mathrm{R}$ station rainfall data.

Budapest can be regarded as a representative twentieth century station for the climatic conditions of the 'ancient' Hungary (Rácz, 1999). Zurich has been chosen as the appropriate station to represent the Swiss Plateau. The Icelandic sea ice data were prepared by Wallevik and Sigurjónsson (1998). The Icelandic data from the recent century refer to the number of weeks during which the northern coasts of Iceland were affected by sea ice from October to September of the following year. Seasonal means of the number of weeks with sea ice were calculated from the yearly sums: winter (December-February) and summer (June-August) contribute 20\% each, spring (March-May) accounts for $60 \%$. For autumn sea ice can be neglected, although it is apparent in some exceptional years. The Western Baltic sea ice severity indices for the twentieth century were prepared by Koslowski and Glaser $(1995,1999)$. The monthly mean wind direction data for Øresund were provided by T. Schmith, E. Kaas, P. Frich and K. Frydendahl (Danish Meteorological Institute, DMI). Since the reconstructed German temperature data for the LMM refer to a broader region of southern Germany, the respective indexed values for the twentieth century were calculated by averaging the monthly means of the stations Erfurt, Frankfurt, Würzburg, Nürnberg and Augsburg (from 1914 onwards). Erfurt has missing values between 1940 and July 1946; Augsburg has two gaps, one between February and December 1944 and another from October to December 1970. The station time series for the twentieth century were not checked for homogeneity or for effects of urbanization.

2.2.2. Predictand data (gridded monthly $S L P$ ). The dependent variables (predictands) consist of gridded monthly mean sea level pressure (SLP) on a $5^{\circ} \times 5^{\circ}$ latitude by longitude grid containing 96 grid points and extending from $25^{\circ} \mathrm{W}$ to $30^{\circ} \mathrm{E}$ and from $35^{\circ}$ to $70^{\circ} \mathrm{N}$ (see Figure 1(a)). The monthly SLP data for the period 1901-1990 (December 1944 is missing) were prepared by the National Center for Atmospheric Research, Boulder, CO, USA (NCAR, 1997). Missing grid point pressure values for some months prior to 1940 were replaced by linear interpolation between adjacent grid points. This data set was checked critically by Trenberth and Paolino (1980) who found no substantial data problems for the area of the North Atlantic and Western Europe. 


\section{RECONSTRUCTION METHOD}

The statistical model used in this reconstruction study is based on a CCA that optimally identifies related pairs of patterns in two multivariate data sets, and constructs sets of transformed variables by projecting the original data onto these patterns (Wilks, 1995). The CCA defines systematic linear relationships between multicomponent predictands - that is, pattern-to-pattern relationships in space and/or time (Barnett and Preisendorfer, 1987), such that the sum of the squared errors is minimized. The CCA effectively and optimally summarizes the linear relationships between large-scale patterns of the atmospheric circulation (predictands) over the North Atlantic-European area and proxy and measured station data (predictors). Thus, CCA determines the pairs of the spatial patterns of the gridded SLP and the stations' climatological conditions such that their time components are optimally correlated, i.e. it establishes the modes of joint variability between the two fields. The detailed mathematical treatment can be found in Anderson (1984), Barnett and Preisendorfer (1987), Bretherton et al. (1992), Cook et al. (1994), von Storch (1995), Wilks (1995) and von Storch and Zwiers (1999).

The overall reconstruction procedure thus consists of

(i) Selection of two sub-periods in the twentieth century, one to calibrate (1901-1960) and one to verify (1961-1990) the statistical models.

(ii) Normalization of the predictors (station data) and the predictands (gridded SLP fields) for each month separately by subtracting the respective mean and dividing by the respective standard deviation, based on the data from 1901 to 1960.

(iii) Correlation-based CCA for developing the statistical models linking the predictors to the predictands for the calibration period (1901-1960) by using a limited number of canonical pairs explaining a large amount of variance; due to varying relationships between the meteorological variables, separate seasonal equations had to be developed (i.e. winter is December, January and February). The three concatenated normalized months for each season were considered as one large vector.

(iv) Verification of the CCA model using the data of the independent observations (1961-1990) including spatial and overall performance for both the calibration and verification periods.

(v) Application of the CCA model based on the data of the calibration period (1901-1960) in order to reconstruct gridded monthly SLP data for the LMM. For reconstructing one particular month within a season the vector is split again and transformed back (based on the respective mean and standard deviation) using equations relating the pressure at each grid point in terms of all the station data. Since the station data series are partially incomplete within the LMM, i.e. temperature and pressure at Paris as well as the Øresund wind direction (see Table I), 20 models with different combinations of the predictor variables had to be developed and applied.

The same method has recently been applied to reconstruct monthly grid point-based and station-based atmospheric circulation indices (NAO and EU) back to AD 1675 (Luterbacher et al., 1999).

A variety of criteria are used to test the 'significance' of a canonical correlation analysis. Jobson (1992) uses the total cumulated redundancy measure as a criterion for how many canonical pairs to retain. In our analysis we, therefore, used only the first few canonical pairs, which explain $\geq 95 \%$ and $\leq 98 \%$ of total redundancy. This decision was based on the development of the mean absolute error (MAE) and root-mean-square error (RMSE), two frequently used verification measures for model performance (e.g. Murphy, 1995; Brooks and Doswell, 1996), for the calibration and verification periods. RMSE and MAE revealed the most accurate forecast showing a slight minimum of around $95 \%$ of total redundancy (not shown). Wilks' Lambda test (Bartlett, 1941) is not applied in our analysis because it is questionable whether the normality assumption is fulfilled and whether independence exists between the consecutive months which are included in the model.

Following the advice of Neter et al. (1990), it is appropriate to use the results of the CCA from the fitting model (1901-1960) for estimating the final regression model for the LMM, even though it is customary practice to use the entire data set (1901-1990). Essentially, the same results were obtained when the LMM SLP reconstructions were based on the whole period of 1901-1990. To test if the results 
are not statistical artifacts of small sample size of the calibration and verification periods within the twentieth century we performed a similar analysis with different sub-intervals (calibration period 1931-1990; verification period 1901-1930). The results did not change significantly, indicating the stable quality of our reconstructions.

\section{OVERALL AND SPATIAL PERFORMANCE OF THE STATISTICAL MODEL}

\subsection{Validation, verification and model performance in the twentieth century}

In order to evaluate model performance, insofar as the circulation of the atmosphere is concerned, we compare the grid point sea level reconstructions (predictions) with the corresponding analysed (or observed) SLP conditions. This comparison is generally accomplished by computing an overall measure of the degree of association or correspondence between the two investigated fields. In the next sections we follow a similar method to that of Jones et al. (1999) to assess the model reconstructions by using several statistical measures.

4.1.1. Overall model performance. Overall model performance for the calibration (1901-1960) and verification (1961-1990) periods can be assessed by calculating the fraction of variance explained across the whole 96 grid point region. Each mode (canonical pairs) of optimally related patterns between SLP fields and station data is characterized by its percentage of total redundancy (see Section 3) (Jobson, 1992). The maximum number of canonical pairs that can be extracted from our data is equal to the number of variables in the smaller of the two groups. Therefore, in winter, 21 canonical pairs can be extracted, in spring and summer 19, and in autumn 18. Taking all canonical variables into account, the total cumulated redundancy for the calibration period is highest in winter $(69.9 \%)$, followed by spring $(58 \%)$, autumn $(57.1 \%)$ and summer $(45.1 \%)$. Figure 2 illustrates the total cumulated redundancy versus the number of retained canonical pairs for the calibration period for all seasons. The canonical pairs are therefore ordered with decreasing percentage of total redundancy. For winter, spring and autumn, 11 canonical pairs were retained accounting for $96 \%$ (96\% of $\sim 70 \%, \sim 58 \%$ and $57 \%$, respectively, of total redundancy), while for summer, 14 canonical pairs were kept, accounting for $95 \%$ of total redundancy. As expected, in all seasons the first canonical pairs explain almost all of the total redundancy, while the remaining higher-order canonical pairs contribute less to the overall variance. No notable changes were found in the reconstruction results using different CCA truncations.

Based on the backward elimination technique, it is possible to remove the least important predictor variable from the regression equation in order to get an impression of the relevant predictors most directly responsible for the physical phenomenon associated with the predictand (SLP fields) (Wilks, 1995). In this study, we have used the same approach as recently applied with success by Tinguely (1998), who investigated the importance of different European stations based on monthly pressure, temperature and

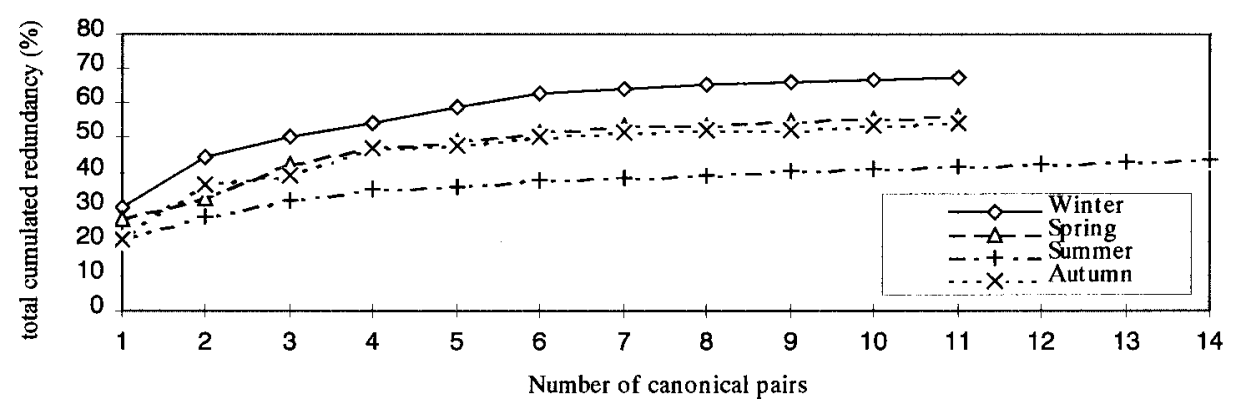

Figure 2. Total cumulated redundancy (in \%) depending on the number of canonical pairs for all seasons in the calibration period (1901-1960). The respective numbers of canonical pairs for each season were retained for the final reconstructions explaining $\geq 95 \%$ and $\leq 98 \%$ of total redundancy. 
rainfall data for the period 1901-1990 as predictors in reconstructing 'optimal' spatial and overall performance of the SLP pattern over Europe. Our results are summarized in Table II showing the backward elimination of the station variables for the four seasons during the fitting period (1901-1960).

The application of backward elimination shows that station pressure from Paris is the most important predictor for the gridded SLP for all seasons. With the exception of autumn, it explains almost half of the total redundancy. Other important variables are the indexed temperature from Zurich (except for winter and spring), the CET and the measured temperature from Paris. In addition, the mean monthly wind direction at the Øresund also contributes significantly to the overall performance, especially in autumn. The three most important variables for each season explain $63 \%$ in autumn, $67 \%$ in spring and summer, and $82 \%$ in winter, of total redundancy. The unimportant variables are generally indexed rainfall data from the Mediterranean area, except for winter. The three least important variables together account only for around $1.5 \%$ of the total redundancy. The Icelandic Sea Ice Index does not contribute much to the overall performance, even in the Icelandic area. It is assumed that the signal of this variable does not show a simultaneous reaction in European-North Atlantic pressure behaviour. There are indications that Icelandic sea ice is advected to the Labrador Sea in a few years. Interannual variations in sea ice extent in the North Atlantic-arctic region and connection with atmospheric circulation. It is, therefore, assumed that the influence will increase with a lag of 2 to 3 years, but this has not been investigated.

4.1.2. Spatial model performance. In order to consider the spatial details of the reconstruction, it is necessary to compare the results with the observed time series, grid point by grid point, over the whole defined region, season by season, for both the calibration and verification periods (Gordon et al., 1985; Jones et al., 1987, 1999).

The strength of the linear statistical relationship between reconstruction (prediction) and observation (analysed fields) can be measured by the square of the correlation coefficient (the coefficient of determination; CoD):

Table II. Backward elimination of the station variables for the four seasons during the fitting period 1901-1960 (in decreasing order of importance)

\begin{tabular}{llll}
\hline Winter & Spring & Summer & Autumn \\
\hline P-Paris & P-Paris & P-Paris & P-Paris \\
T-Central-England & T-Southern Germany & T-Central-England & DD-Øresund \\
DD-Øresund & T-Paris & T-Zurich & T-Zurich \\
R-Sevilla & R-Sevilla & DD-Øresund & R-Lisbon \\
T-Paris & DD-Øresund & T-Athens & T-Paris \\
T-Budapest & T-Lisbon & T-Lisbon & R-Zurich \\
R-Zurich & T-Zurich & R-Barcelona & R-Madrid \\
R-Kew & T-Budapest & Icelandic Sea Ice & T-Athens \\
R-Madrid & R-Barcelona & R-Budapest & R-Hungary \\
R-Athens & T-Central-England & R-Madrid & T-Lisbon \\
T-Southern Germany & R-Zurich & R-Kew & R-Athens \\
R-Barcelona & T-Athens & R-Lisbon & T-Central-England \\
T-Lisbon & R-Murcia & T-Paris & T-Southern Germany \\
T-Athens & R-Kew & T-Southern Germany & R-Kew \\
R-Budapest & R-Budapest & T-Budapest & R-Barcelona \\
R-Lisbon & Icelandic Sea Ice & R-Murcia & R-Murcia \\
R-Murcia & $R$-Athens & $R$-Sevilla & R-Sevilla \\
Icelandic Sea Ice & $R$-Lisbon & $R$-Athens & T-Budapest \\
$T$-DeBilt & $R$-Madrid & $R$-Zurich & \\
Baltic Sea Ice & & & \\
$T$-Zurich & & & \\
\end{tabular}

The three most important variables for each season are in bold, the three least important variables are in italics. 
For the evaluation of the spatial model performance in the calibration and verification period, the CoD is

$$
\mathrm{CoD}=1-\frac{\sum_{j}\left(y_{j t}-\hat{y}_{j t}\right)^{2}}{\sum_{j}\left(y_{j t}-\bar{y}_{j}\right)^{2}},
$$

where $y_{j t}$ is the observed pressure value at grid point $j$ for month $t$ within the respective season in the calibration (verification) period. Index $j$ covers all months within each season over all the years from 1901 to 1960 (calibration period) and from 1961 to 1990 (verification period), respectively. $\hat{y}_{j t}$ is the regression function of the fitted values and $\bar{y}_{j}$ is the seasonal mean pressure value of each of the 96 grid points in the calibration (verification) period. We therefore obtain one CoD map for each season separately for the calibration and verification period. The reliability of the reconstruction can only be truly evaluated by examining the reconstructed SLP distribution for years independent of the calibration period. Therefore, only the performance of the CCA model with maximum number of predictors for all seasons over the verification period (1961-1990) according to Equation (1) is given (Figure 3). Similar to the study of Jones et al. (1999), our isoline plots (Figure 3) of explained variance bear some resemblance to concentric circles with tighter contours in summer, meaning greater losses of variance around the periphery of
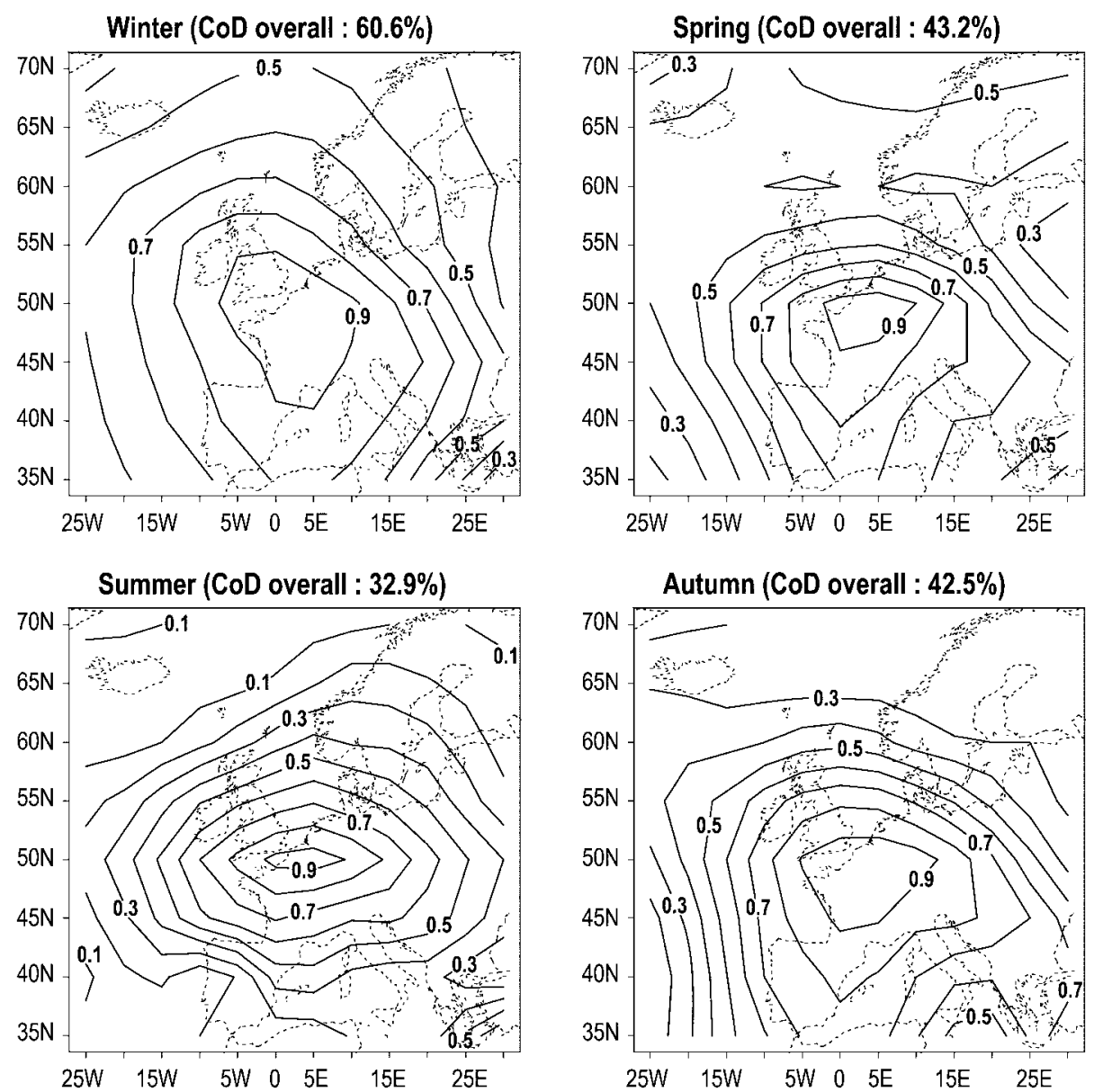

Figure 3. The spatial performance of the CCA model with the maximum number of predictors for each season determined by the CoD over the verification period (1961-1990). 
Europe. Over Central Europe, as well as for the northwestern and eastern European regions, good estimates, which cover broad regions with more than $80 \%$ explained variance, are reached. In summer, the $\mathrm{CoD}$ decreases very rapidly from the centre situated over northwestern France, towards the periphery of the grid. In summer, the climatic conditions in Central Europe are mainly influenced by regional scale processes and are more sensitive to local forcing related to insolation distributions and the high sensitivity to local lower boundary conditions (soil moisture). The poor spatial performance during this season can be attributed to the large-scale synoptic situation, which is characterized by a dispersed convective precipitation pattern and small pressure gradients, which cannot be explained with the climate information from the different stations. The spatial performance in the southeastern Mediterranean and the Balkans is excellent during summer and autumn, with $70-80 \%$ of shared variance. Surprisingly, the amount of shared variance in the Azores region is some percent higher in the verification period compared with the calibration period (not shown). This is an important finding for the study of the reliability of the reconstructed North Atlantic Oscillation Index (NAOI) (Luterbacher et al., 1999). The model performs least well at the periphery of the grid, where only a very small portion of variance can be shared. Thus, reconstruction results in these regions cannot be readily obtained by extrapolation from other regions. Similar results were obtained by Jones et al. (1999). There is, as is to be expected, a loss in explained variance between the calibration and verification periods in all seasons; this is of the order of 5-20\% (depending on the season and the area under consideration) (not shown).

We also followed the reconstruction technique used by Jones et al. $(1987,1999)$ who used a PCA followed by a multivariate regression (which is equivalent to a CCA analysis after the PCA including all possible canonical pairs) and compared the reconstruction results with our CCA results based on the original normalized data (not shown). Further, we tested the approach by projecting the original data of the two fields onto their PCs before subjecting them to a CCA, retaining only a limited number of them in order to avoid noise. In both cases, essentially the same results were obtained without overall improvement. In addition, we applied the methods of 'Maintenance of Variance Extension' MOVE (Type 1 and Type 2) proposed by Hirsch (1982), which do not set the intercept (a) and slope (b) of the linear regression equations to minimize squared errors for estimation grid point pressure, but rather to maintain the sample mean and the variance. The SLP estimates for the twentieth century did not improve the final results. Although the different techniques exhibited minor differences in their overall and spatial performance, the selection of one method in preference to another does not appear to influence the reconstruction significantly.

The backward elimination technique for 1961-1990 reveals similar results about the importance, or irrelevance, of specific predictors for the fitting period. Table III shows the summary of the elimination procedure. Paris pressure is still the most important variable, explaining from $30 \%$ (winter) up to $50 \%$ (summer) of total redundancy. However, some variables changed their importance. The three most important variables for each season explain two thirds of the total redundancy while the contribution of the three least important predictors is only about $2 \%$.

In summary, the spatial performance for both the calibration and verification periods indicates that grid point air pressure reconstructions are of good quality. Considerable poorer reconstructions at the individual grid points are obvious for regions with little or no data, especially during the summer. Nevertheless, it is still possible to define large-scale atmospheric pressure patterns despite 'errors' at individual grid points at the fringes of Europe.

4.1.3. Spatial anomaly correlation performance. The anomaly correlation (AC) is a commonly used measure of association that operates on pairs of grid point values in the predicted and observed fields by calculation of spatial anomaly correlation coefficients over all grid points (Wilks, 1995). To compute the $\mathrm{AC}$, the reconstructed and analysed grid point values are first converted to anomalies, in the sense that the climatological average value of the calibration period (1901-1960) at each grid point is subtracted. The reconstructed and analysed data are compared over all the analysed grid points for each month separately (Jones et al., 1987, 1999). Figures 4 and 5 show the time series of AC for 1901-1990 for the four central months of each season (January, April, July and October) for the best CCA model. In 
Table III. Backward elimination of the station variables for the four seasons during the verification period 1961-1990 (in decreasing order of importance)

\begin{tabular}{llll}
\hline Winter & Spring & Summer & Autumn \\
\hline P-Paris & P-Paris & P-Paris & P-Paris \\
T-Central-England & T-Zurich & T-Budapest & T-Southern Germnay \\
R-Zurich & T-Paris & R-Madrid & DD-Øresund \\
T-Lisbon & R-Zurich & R-Budapest & R-Lisbon \\
R-Sevilla & DD-Øresund & T-Athens & T-Central England \\
R-Athens & T-Southern Germany & T-Lisbon & R-Budapest \\
DD-Øresund & R-Athens & DD-Øresund & T-Lisbon \\
R-Kew & R-Madrid & R-Lisbon & R-Barcelona \\
Baltic Sea Ice & T-Athens & T-Paris & R-Kew \\
R-Murcia & R-Kew & R-Sevilla & T-Athens \\
R-Madrid & T-Lisbon & R-Kew & R-Athens \\
Icelandic Sea Ice & T-Budapest & R-Athens & R-Madrid \\
R-Budapest & R-Sevilla & T-Central-England & R-Sevilla \\
T-Budapest & R-Budapest & R-Barcelona & T-Paris \\
T-Paris & Icelandic Sea Ice & Icelandic Sea Ice & R-Murcia \\
T-Zurich & T-Central-England & T-Southern Germany & T-Zurich \\
T-Southern Germany & R-Murcia & R-Murcia & R-Zurich \\
T-DeBilt & $R$-Barcelona & $R$-Zurich & T-Budapest \\
R-Lisbon & $R$-Lisbon & $R$-Zurich & \\
R-Barcelona & & & \\
$T$-Athens & & & \\
\hline
\end{tabular}

The three most important variables for each season are in bold, the three least important variables are in italics.

addition, the MAE is calculated and included in Figures 4 and 5 in order to account for biases in the twentieth century reconstructions.

As expected, the AC are generally higher for the calibration period (1901-1960) compared with the verification period (1961-1990). In addition, the variability of the AC is larger for 1961-1990. In some years, even negative correlations are evident; an indication of poor reconstruction quality in these years for the respective month. The MAE for the different months is generally low and does not show any
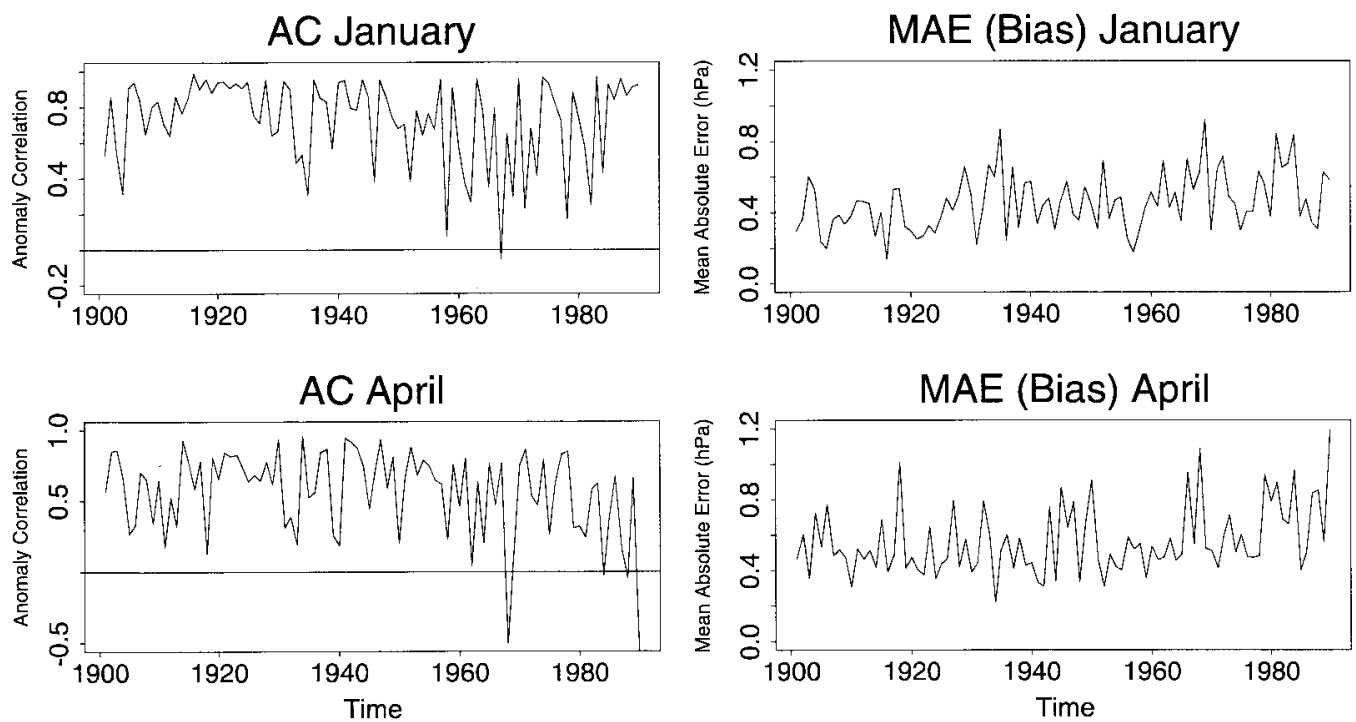

Figure 4. Time series of anomaly correlations (AC) and MAE 1901-1990 for January and April for the best CCA model. 

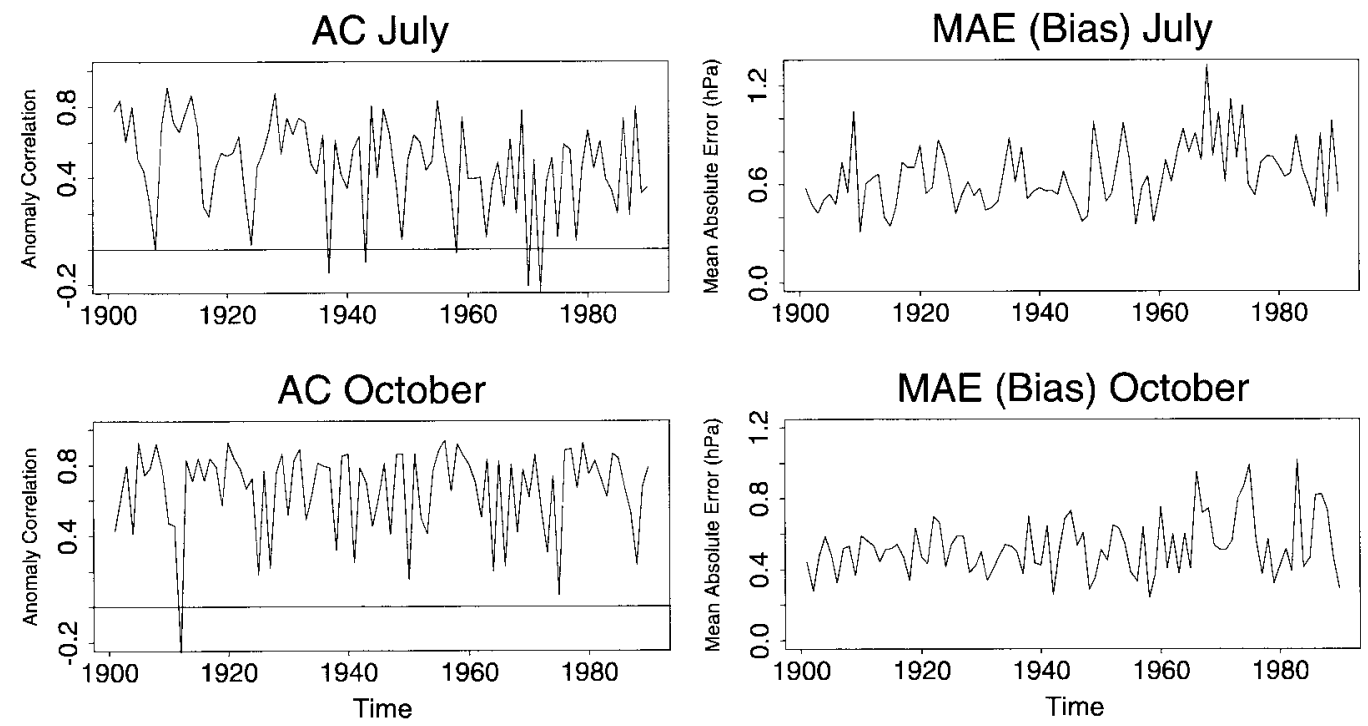

Figure 5. As for Figure 4 but for July and October.

systematic bias over the whole 90 years, although slightly higher values are prevalent during the verification period.

\section{VERIFICATION OF THE SLP CHARTS AND COMPARISON WITH EARLIER LMM RECONSTRUCTIONS}

Even if independent instrumental data are available to verify a reconstruction, verification is often limited to periods with climatic conditions similar to those used for calibration. Comparisons with natural or documentary proxy evidence become necessary to assess the reconstructions' reliability over longer time scales. Comparisons with independently derived proxy climate records are important for establishing a spatially detailed and reliable picture of climatic variations prior to instrumental records (Gordon et al., 1985). There are some important sporadic, non-continuous data (measured and proxy) available in the LMM that have the potential to estimate the reconstruction quality, at least in some parts of Europe.

As a first approach to comparing our reconstruction results with important omitted data from the LMM, we used the available dominant monthly wind directions for Paris, Kew and Breslau and compared them visually with the prevailing circulation indicated by the reconstructions in the vicinity of these locations. For Paris and Kew, in more than $75 \%$ of all LMM months, the main dominant wind direction data are available, for Breslau less. The winter, summer and autumn months, in particular, indicate good reconstruction results, with around $80 \%$ of months in agreement with the predominant circulation. More than $60 \%$ of the spring months correspond with the dominant pressure pattern, and $25 \%$ of the remaining $40 \%$ showed only small differences in wind directions which is, again, an indication of reliable reconstructions.

Since the dominant wind directions from Kew and Paris are mostly from the western sector, they serve as verification, especially during winter months, for the advection of maritime air masses to the British Isles and western Europe. They are, therefore, an indication for a positive phase of the NAO. Dominant winds from the north or east (negative phase of the NAO) are rare in these areas and are generally connected with below normal temperature. Accordingly, in order to test the reliability of the prevailing pressure conditions other variables are needed which can give some indication of the climatic conditions over continental and eastern Europe. Similar results to those for Paris and Kew have been obtained for the Breslau wind readings. Another independent, sporadic variable to test our reconstructions is the 
compilation of reconstructed severe years with warm/cold and wet/dry conditions for Moscow and its surroundings and for the western Ukraine (Lyakhov, 1987; Borisenkov, 1994). Climate indications from these regions related to severe precipitation and winter temperature can serve as 'tracers' for prevailing air masses. They give an indication of the pressure situation at the eastern border of the reconstruction region. In addition, this area also serves as a source of cold air masses during winter, which are advected to central Europe. According to Lyakhov (1987) and Borisenkov (1994), the years 1675-1679, 1695-1697 and 1708-1709 were extremely cold in Russia. In addition, similar climatic indications are found for Romania from documentary evidence and chronicles, although information is not available for every winter mentioned (Boroneant and Chiper, 1998). It is assumed that a strong high pressure system was situated over Scandinavia or northern Russia, leading to cold air advection from an easterly direction. Our reconstructions support strong anticyclonic pressure patterns over these areas for the winters 1675-1676, 1679-1680, 1695-1696-1697 and 1708-1709. The known dry spring/ summer season 1698 in western Russia, is not confirmed by our reconstructions, which show low pressure situations in almost all months, indicating rather rainy conditions. In contrast, the three rainy and cold spring/summer seasons of 1681, 1695 and 1697 in the western part of Russia (Lyakhov, 1987) and Romania (Boroneant and Chiper, 1998) are in good agreement with our SLP patterns, which indicate cyclonic circulation with a low centred over Scandinavia. In general, the thermic and hygric reconstructions of Lyakhov (1987) for the late seventeenth and early eigtheenth century for western Russia, as well as the indication from Romania (Boroneant and Chiper, 1998), show good agreement with our SLP reconstructions. This is another indication that at least the postulated severe years in the eastern part of the grid are reasonably estimated, although no data were included in our model.

We compared our reconstructions visually with the results of Wanner et al. (1994) and Hochstrasser (1995) to see whether or not these earlier subjective approaches resulted in similar circulation patterns to the maps obtained with our objective procedures. In relative terms only in about $50 \%$ of all winter and spring months from 1675 to 1704 (reconstructed by Wanner et al., 1994) are there distinct discrepancies in the location of the dominant air pressure patterns, except for severe years like 1695 or 1709. In summer and autumn, completely different patterns were obtained in our study as compared with the results of Hochstrasser (1995) (not shown).

\section{DISCUSSION AND CONCLUSIONS}

Based on several continuous European station records (indexed and partly measured), monthly mean SLP patterns were reconstructed for the period $1675-1715$ based on a CCA. The verification results from the twentieth century illustrate that the regression equations developed contain good predictive power for the large majority of grid points. A grid point by grid point comparison of the CoD for the calibration period (1901-1960) with the explained variance for the verification period (1961-1990) shows that there is a relationship between these correlations. In other words, a large (small) amount of explained variance for areas in the calibration period coincide with well (poorly) reconstructed regions in the verification period. Therefore, there are limitations, both in season and area, for a good spatial SLP reconstructions. The model does not show any systematic deficiency as far as the spatial and overall performance is concerned. However, reliable monthly SLP estimations for parts of the study area depend strongly on the respective season. The results obtained both for the calibration and verification period in the twentieth century point to a rather poor quality of LMM reconstructions at the periphery of the SLP grid, especially for the summer months (except for the southeastern part of Europe). In addition, the quality of the reconstructions for the first few and the last few months of the LMM are lower. This can be attributed to the missing station pressure and temperature at Paris, which are the most important predictors. For these months, the loss of explained variances over the whole grid is of the order of $10-15 \%$, depending on the season. 
In their comparative study of different spatial regression methods in dendroclimatology, Cook et al. (1994) were able to show that the results from the CCA and the principal component multivariate regression method are similar, as long as the relationships between the predictors and predictands are strong. This is in agreement with our comparison between the different reconstruction techniques described in Section 4.1, a result that is not surprising since similarity between the models can be explained by the fact that each method is based on least-squares theory. Nevertheless, we believe that CCA works optimally when the relationship between two data sets is analysed with the original normalized data. This is because CCA eliminates the 'noise in common' between the two data sets, whereas data pre-filtering with a PCA can exclude potentially useful information shared by the two data sets, even though it has the advantage of eliminating noise in each data set separately and makes CCA less susceptible to sampling fluctuations due to short time series (Barnett and Preisendorfer, 1987). Furthermore, CCA tends to be overestimated if the number of PCAs is too large and a (subjective) compromise is needed between the requirement of having a highly explained variance and the constraint regarding the noise from the data (von Storch, 1995; von Storch and Zwiers, 1999).

There is always the reservation that indexed data are connected with a huge loss of information compared with instrumental data and therefore any climate reconstructions tend to be more 'speculative' and probably less representative for broader areas. Therefore, we compared the difference in performance of the CCA model in the present century by using only observed and only indexed predictors (not shown) in order to assess the quality of the documentary reconstructions. The visual comparison of the predicted fields based on measured station data and indexed data reveal good correspondence between the location of the pressure centres and also the prevailing pressure gradient for most of the months, an indication of the reliability and general acceptability of reconstructions based on proxy data. Nevertheless, the use of indexed values lead to a reduced overall and spatial performance of all seasons of the order of $10-20 \%$ of the explained variance, for both the fitting and the verification periods. Thereby, the loss of information is not equally distributed over Europe.

With Paris air pressure and temperature, CET, indexed Zurich temperature and monthly mean wind direction from the Øresund, a significant amount of variance can be explained even at the edges of the pressure grid. Only a small number of single series allow reconstruction of the monthly SLP distribution over Europe to a reasonable degree. The method emphasizes the value of reliable time series. Therefore, an incorrect temperature or pressure observation for Paris will result also in a wrong SLP distribution. However, the indexed time series improve the quality of the reconstructions, especially around the region of the instrumental data. One or two probable erroneous temperature or hygric indices, for different stations in a particular month, do not change the reconstructed monthly fields, indicating rather stable reconstruction results.

Our reconstructions in comparisons with earlier subjective estimations of the mean atmospheric flow during the LMM showed pronounced differences. In winter and spring, the most anomalous months are in agreement with our reconstructions, whereas the 'normal' months show quite different patterns. It cannot be proven that our reconstructions are more reliable than the hand-drawn charts, which do include a lot of synoptic experience. However, our maps are based on more data in all regions of Europe and on an objective analysis. As was pointed out in Section 4, particularly for winter, but also for the transitional seasons, the reconstruction skill for the verification period in the twentieth century is very good over large areas of Europe. This, therefore, implies qualitatively good reconstructions for the LMM, which is supported by important data not included in the reconstruction procedure.

In additional papers, we present an analysis of the LMM atmospheric circulation dynamics and synoptic investigations of interannual and interdecadal differences as compared with the twentieth century, with the goal of obtaining insight into the feedback mechanisms between the ocean, atmosphere and sea ice, which led to the climate variability of this period (Luterbacher and Pfister, 1999; Luterbacher et al., 2000). In addition, comparisons with different periods, such as the pressure reconstructions from 1780 onwards (Jones et al., 1999), will be continued (Luterbacher and Pfister, 1999; Luterbacher et al., 2000). 


\section{ACKNOWLEDGEMENTS}

This work is part of the ADVICE project, funded by the European Commission under contract ENV4-CT95-0129. The Swiss project was funded by the Bundesamt für Bildung und Wissenschaft (BBW) under contract 95.0401. The authors wish to thank Ms Mary Brown for proof reading the English text. Thanks also to Constanta Boroneant (Bucharest), Gerhard Koslowski (Neu Wulmstorf), Rudolf Brázdil (Brno) and Christoph Schmutz (Bern) for fruitful discussions and suggestions. The authors also wish to thank Povl Frich (Copenhagen) for providing monthly wind data from the Øresund.

\section{REFERENCES}

Alcoforado MJ, Nunes MF, Garcia JC, Taborda JP. 2000. Temperature and precipitation reconstructions in southern Portugal during the Late Maunder Minimum (1675-1715). The Holocene 10 (in press).

Anderson CW. 1984. An Introduction to Multivariate Statistical Analysis (2nd edn). Wiley: New York; 675.

Barnett T, Preisendorfer R. 1987. Origins and levels of monthly and seasonal forecasts skill for United States surface air temperature determined by canonical correlation analysis. Monthly Weather Review 115: 1825-1850.

Bartlett MS. 1941. The statistical significance of canonical correlations. Biometrika 32: 29-38.

Beer J, Mende W, Stellmacher R, White OR. 1996. Intercomparison of proxies for past solar variability. In Climatic Variations and Forcing Mechanisms of the Last 2000 Years, Jones PD, Bradley RS, Jouzel J (eds). Springer: Berlin; 503-516.

Borisenkov YP. 1994. Climatic and other natural extremes in the European territory of Russia in the late Maunder Minimum (1675-1715). In Climatic Trends and Anomalies in Europe 1675-1715, Frenzel B, Pfister C, Gläser B (eds). Fischer: Stuttgart; $83-94$.

Boroneant C, Chiper M. 1998. Climatic anomalies in Romanian territory compared to the climate of Europe in the years of Maunder Minimum (1675-1715). In Second International Climate and History Conference. Norwich, UK, September; 7.

Bradley RS, Jones PD. 1993. Little Ice Age summer temperature variations: their nature and relevance to recent global warming trends. The Holocene 3: 367-376.

Brázdil R, Dobrovolny P, Chocholác B, Munzar J. 1994. Climatic and other natural extrems in the European territory of Russia in the Late Maunder Minimum (1675-1715). In Climatic Trends and Anomalies in Europe 1675-1715, Frenzel B, Pfister C, Glaeser B (eds). Fischer: Stuttgart; 83-94.

Bretherton CS, Smith C, Wallace JM. 1992. An intercomparison of methods for finding coupled patterns in climate data. Journal of Climate 5: 541-560.

Briffa KR, Wigley TML, Jones PD, Pilcher JR, Hughes MK. 1987. Patterns of tree-growth and related pressure variability in Europe. Dendrochnologia 5: 35-59.

Briffa KR, Jones PD, Schweingruber FH, Osborn TJ. 1998. Influence of volcanic eruptions on Northern Hemisphere summer temperature over the past 600 years. Nature 393: 450-455.

Brooks HE, Doswell III CA. 1996. A comparison of measures-oriented and distributions-oriented approaches to forecast verification. Weather Forecasting 11: 288-303.

Cook ER, Briffa KR, Jones PD. 1994. Spatial regression methods in dendroclimatology - a review and comparison of two techniques. International Journal of Climatology 14: 379-402.

Damon PE, Jirikowic JL. 1994. Solar forcing of global climate change. In The Sun as a Variable Star, Pap JM, Fröhlich C, Hudson HS, Solanki SK (eds). Cambridge University Press: Cambridge; 301-314.

Eddy JA. 1976. The Maunder Minimum. Science 192: 1189-1202.

Frydendahl K, Frich P, Hansen C. 1992. Danish weather observations 1675-1715. DMI Technical Report 92-3, Danish Meteorological Institute (DMI), Denmark-2100 Copenhagen; 23.

Glaser R. 1997. Beiträge zur Historischen Klimatologie in Mitteleuropa seit dem Jahr 1000. Habilitationsschrift Universität Würzburg: Würzburg.

Glaser R, Beyer U, Beck C. 1999. Weighted hygric and thermal indices from Germany 1500 bis 1995. Unpublished data from the HISKLID database and instrumental observations (in German), Institute of Geography, University of Würzburg, Germany.

Gordon GA, Lough JM, Fritts HC, Kelly. PM. 1985. Comparison of sea level pressure reconstructions from Western North American tree rings with proxy record of winter severity in Japan. Journal of Climate and Applied Meteorology 24: $1219-1224$.

Hirsch RM. 1982. A comparison of four streamflow record extension techniques. Water Resources and Research 18: $1081-1088$.

Hochstrasser F. 1995. Rekonstruktion von monatlichen Bodendruckfeldern in den Sommer- und Herbstmonaten des späten Maunder Minimums (1675-1705) in Europa und Ternperatur- und Niederschlagsvergleich mit der Normalperiode 1961-1990. M. Thesis, Geographisches Institut, Universität Bern; 225.

Hoyt DV, Schatten KH. 1993. A discussion of plausible solar irradiance variations, 1700-1992. Journal of Geophysical Research 98: $18895-18906$.

Jobson DJ. 1992. Applied Multivariate Data Analysis, vol. II. Springer: Berlin.

Jones PD, Wigley TM, Briffa KR. 1987. Monthly mean pressure reconstruction for Europe (back to 1780) and North America (back to 1858). DOE Technical Report No. TR37. US Department of Energy, Washington DC, 99 pp.

Jones PD, Briffa KR, Barnett TP, Tett SFB. 1998. High-resolution palaeoclimatic records for the last millennium: interpretation, integration and comparison with General Circulation Model control-run temperatures. The Holocene 8: 455-471.

Jones PD, Davies TD, Lister DH, Slonosky V, Jónsson T, Bärring L, Jónsson P, Maheras P, Kolyva-Machera F, Barriendos M, Martin-Vide J, Alcoforado MJ, Wanner H, Luterbacher J, Rickli R, Pfister C, Schüpbach E, Kaas E, Schmith T, Jacobeit J, Beck C. 1999. Monthly mean pressure reconstruction for Europe 1780-1995. International Journal of Climatology 19: $347-364$.

Kington J. 1995. The severe winter of 1694/95. Weather 50: 160-163. 
Kington J. 1997. The severe winter of 1696/97. Weather 52: 386-391.

Kington J. 1999. The severe winter of 1697/98. Weather 54: 43-49.

Koslowski G, Glaser R. 1995. Reconstruction of the Ice Winter Severity since 1701 in the Western Baltic. Climatic Change 31: $79-98$.

Koslowski G, Glaser R. 1999. Variations in reconstructed Ice winter severity in the Western Baltic from 1501 to 1995 , and their implications for the North Atlantic Oscillation. Climatic Change 41: 175-191.

Lamb HH. 1977. Climate, Present, Past and Future: Volume 2. Climatic History and the future. Methuen: London; 835.

Lamb HH. 1982. Climate, History and the Modern World. Methuen: London.

Lean J, Beer J, Bradley RS. 1995. Reconstruction of solar irradiance since 1610: implications for climate change. Geophysical Research Letters 22: 3195-3198.

Lean J, Rind D. 1998. Climate forcing by changing solar radiation. Journal of Climate 11: 3069-3094.

Lean J, Rind D. 1999. Evaluating sun-climate relationships since the little ice age. Journal of Atmospheric and Solar-Terrestrial Physics 61: 25-36.

Legrand J-P, Le Goff M. 1992. Les observations météorologiques de Louis Morin entre 1670 et 1713 . In Direction de la Météorologie Nationale. Monographie Nr. 6. Météo-France: Trappes.

Luterbacher J, Pfister C. 1999. The Late Maunder Minimum (1675-1715)—climax of the Little Ice Age in Europe. In Climate and Climate Impacts through the Last 1000 Years, Jones PD, Davies TD, Ogilvie AEJ, Briffa KR (eds). Climatic Research Unit, University of East Anglia: Norwich (in revision).

Luterbacher J, Schmutz C, Gyalistras D, Xoplaki E, Wanner H. 1999. Reconstruction of monthly NAO and EU indices back to AD 1675. Geophysics Research Letters 26: 2745-2748.

Luterbacher J, Rickli R, Xoplaki E, Tinguel Y, Beck C, Pfister C, Wanner H. 2000. The Late Maunder Minimum (1675-1715) - a key period for studying climatic variability and decadal scale climate change in Europe. Climate Change (in press).

Lyakhov MYe. 1987. Years with extreme climatic conditions. In Data of Meteorological Studies, No. 13 (in Russian). Institute of Geography, Academy of Sciences: Moscow; 119-178.

Maddox J. 1998. Natural antidote to global warming. Nature 377: 193.

Manley G. 1974. Central England temperatures: monthly means 1659 to 1973. Quarterly Journal of the Royal Meteorological Society 100: $389-405$.

Mann ME, Bradley RS, Hughes MK. 1998. Global-scale temperature patterns and climate forcing over the past six centuries. Nature 392: $779-787$.

Martin-Vide J, Barriendos M. 1995. The use of rogation ceremony records in climatic reconstruction: a case study from Catalonia (Spain). Climatic Change 30: 201-221.

Maunder EW. 1922. The prolonged sunspot minimum 1675-1715. British Astronomical Association Journal 32: $140-145$.

Murphy AH. 1995. The coefficients of correlation and determination as measures of performance in forecast verification. Weather Forecasting 10: $681-688$.

NCAR. 1997. Trenberth's northern hemispheric sea level pressure, $5^{\circ} \times 5^{\circ}$, monthly. DSS/D/DS010.1 data set, Boulder, CO.

Nesme-Ribes E, Ferreira EN, Sadourny R, Le Treut H, Li ZX. 1993. Solar dynamics and its impact on solar irradiance and the terrestrial climate. Journal of Geophysical Research 98: 18923-18935.

Neter J, Wasserman W, Kutner MH. 1990. Applied Linear Statistical Models. Regression, Analysis of Variance and Experimental Designs (3rd edn). Irwin: Homewood; 1181.

Ogilvie AEJ. 1992. Documentary evidence for changes in the climate of Iceland, A.D. 1500-1800. In Climate Since A.D. 1500, Bradley RS, Jones PD (eds). Routledge: London; 92-117.

Ogilvie AEJ. 1996. Sea ice conditions off the coasts Iceland A.D. 1601-1850 with special reference to part of the Maunder Minimum period (1675-1715). In AmS-Varia 25, Pedersen EJ (ed.). Archaeological Museum of Stavanger: Norway; 9-12.

Ogilvie AEJ, Jónsdóttir I. 1996. Sea ice incidence off the coasts of Iceland: evidence from historical data and early sea ice maps. In 26th International Arctic Workshop, Arctic and Alpine Environments, Past and Present Program with Abstracts INSTAAR, Boulder, CO, 14-16 March; 109-110.

Parker DE, Legg TP, Folland CK. 1992. A new daily Central England Temperature series, 1772-1991. International Journal of Climatology 12: 317-342.

Peterson TC, Vose R, Schmoyer R, Razuvaë V. 1998. Global Historical Climatology Network (GHCN). Quality control of monthly temperature data. International Journal of Climatology 18: 1169-1179.

Pfister C. 1994. Spatial patterns of climatic change in Europe 1675-1715. In Climatic Trends and Anomalies in Europe 1675-1715, Frenzel. B, Pfister C, Glaeser B (eds). Fischer: Stuttgart; 287-317.

Pfister C. 1999. Wetternachhersage. 500 Jahre Klimavariationen und Naturkatastrophen 1496-1995. Haupt: Bern.

Pfister C, Kington J, Kleinlogel G, Schüle H, Siffert E. 1994. The creation of high resolution spatio-temporal reconstructions of past climate from direct meteorological observations and proxy data. Methodological considerations and results. In Climatic Trends an Anomalies in Europe 1675-1715, Frenzel B, Pfister C, Glaeser B (eds). Fischer: Stuttgart; 329-376.

Rácz L. 1994. The climate of Hungary during the late Maunder Minimum (1675-1715). In Climatic Trends and Anomalies in Europe 1675-1715, Frenzel B, Pfister C, Glaeser B (eds). Fischer: Stuttgart; 95-107.

Rácz L. 1999. Climate History of Hungary since 16th Century: Past, Present and Future. Gál. Pécs.

Siegenthaler D. 1994. Climatic trends and anomalies in England 1675-1715. In Climatic Trends and Anomalies in Europe 1675-1715, Frenzel B, Pfister C, Glaeser B (eds). Fischer: Stuttgart; 133-150.

Spörer FWG. 1887. Uber die Periodizität der Sonnenflecken seit dem Jahre 1618, vornehmlich in Bezug auf die heliographische Breite derselben, und Hinweis auf eine erhebliche Störung dieser Periodizität während eines langen Zeitraumes. Vierteljahrsschrift der Astronomischen Gesellschaft Leipzig 22: 323-329.

von Storch H. 1995. Spatial patterns: EOFs and CCA. In Analysis of Climate Variability. Applications of Statistical Techniques, von Storch H, Navarra A (eds). Springer: Berlin; 227-258.

von Storch H, Zwiers FW. 1999. Statistical Analysis in Climate Research. Cambridge University Press: Cambridge. 
Stuiver M, Braziunas TF. 1993. Sun, ocean, climate and atmospheric ${ }^{14} \mathrm{CO}_{2}$ : an evaluation of causal and spectral relationships. The Holocene 3: 289-305.

Tinguely C. 1998. Vergleich der Bodenluftdruckfelder über Europa mit Klimaparametern ausgewählter Stationen während des 20. Jahrhunderts. M. Thesis, Geographisches Institut, Universität Bern; 73.

Trenberth K, Paolino DA. 1980. The Northern Hemisphere sea level pressure data set: trends, errors and discontinuities. Monthly Weather Review 108: 855-872.

Van den Dool HM, Krijnen HJ, Schuurmans CJE. 1978. Average winter temperatures at De Bilt (Netherlands) 1634-1977. Climatic Change 1: $319-330$.

Vose RS, Richard L, Schmoyer PM, Steurer TC, Peterson RH, Karl TR, Eischeid JK. 1992. The Global Historical Climatology Network: long-term monthly temperature precipitation, sea level pressure, and station data. ORNL/CDIAC-53, NDP-041, Carbon Dioxide Information Analysis Center, Oak Ridge National Laboratory, Oak Ridge, TN, 315 pp.

Wales-Smith BG. 1971. Monthly and annual totals of rainfall representative of Kew, Surrey, from 1697 to 1970. Meteorological Magazine 100: $345-362$.

Wallevik JE, Sigurjónsson H. 1998. The Koch Index. Formulation, corrections and extension. Veðurstofa Íslands Report, Reykjavík, p. 14.

Wanner H, Brazdil R, Frich P, Frydendahl K, Jónsson T, Kington J, Pfister C, Rosenørn S, Wishman E. 1994. Synoptic interpretation of monthly weather maps for the late Maunder Minimum (1675-1704). In Climatic Trends and Anomalies in Europe 1675-1715, Frenzel B, Pfister C, Glaeser B (eds). Fischer: Stuttgart; 401-424.

Wanner H, Pfister C, Brazdil R, Frich P, Frydendahl K, Jónsson T, Kington J, Rosenørn S, Wishman E. 1995. Wintertime European circulation patterns during the Late Maunder Minimum cooling period (1675-1704). Theoretical and Applied Climatology 51: 167-175.

Wilks DS. 1995. Statistical Methods in the Atmospheric Sciences. An Introduction. Academic Press: New York.

World Climate Disc. 1992. Global Climatic Change Data on CD-ROM. Chadwyck-Healey Ltd., Climatic Research Unit (CRU), University of East Anglia: Norwich.

Wuebbles DJ, Wei C-F, Patten KO. 1998. Effects on stratospheric ozone and temperature during the Maunder Minimum. Geophysical Research Letters 25: 523-526.

Xoplaki E, Maheras P, Luterbacher J. 2000. Variability of climate in Meridional Balkans during the period 1675-1715 and its impact on human life. Climate Change (in press).

Yarnal B. 1993. Synoptic Climatology in Environment Analysis. A Primer. Belhaven Press: London.

Yarnal B, Frakes B. 1997. A procedure for blending manual and correlation-based synoptic classification. International Journal of Climatology 17: 1381-1396.

Zhang Q, Soon WH, Baliunas SL, Lockwood GW, Skiff BA, Radick RR. 1994. A method of determining possible brightness variations of the Sun in past centuries from observations of solar-type stars. Astrophysics Journal 427: L111-L114. 